Research Article

\title{
In-situ Stress Measurement and its Engineering Application in Deep Coal Mines: A Case Study in the Xinji Coalfield of China
}

\author{
Liu Qinjie ${ }^{1, *}$, Yang Ke ${ }^{1,2}$, Hua Xinzhu ${ }^{1}$ and Li Bo ${ }^{3}$ \\ ${ }^{1}$ Key Laboratory of Safety and High-efficiency Coal Mining, Ministry of Education (Anhui University of Science and Technology), \\ Huainan 232001, China \\ ${ }^{2}$ Institute of Special Green Mining, Anhui University of Science and Technology, Huainan 232001, China \\ ${ }^{3}$ Case School of Engineering, Case Western Reserve University, Cleveland, 44106, United States
}

Received 19 July 2016; Accepted 15 November 2016

\begin{abstract}
The distribution characteristics of in-situ stress have significant influences on the stability of the surrounding rock masses in deep mine roadways. However, the derivation of a complete calculation formula for the principal stresses by the hollow-inclusion strain gauge (HISG) method and the quantitative application of in-situ stress measurement in the design of roadway support systems in deep mines have been rarely undertaken. Thus, in this study, an HISG method is used to measure the in-situ stress, investigate the in-situ stress state in deep mines, and improve the stability control of roadway surrounding rock masses. A calculation formula for the principal stresses was derived by the HISG method, using a coordinate transformation method. The derivation was based on the elastic deformation hypothesis of a homogeneous isotropic rock, and the deformation analysis theory of a circular hole within the framework of elasticity mechanics. Four deep mines in the Xinji coalfield (Anhui Province, China) were selected to measure the in-situ stress and analyze the magnitudes, orientations, and dips of the principal stresses. The depths of these points ranged from $605 \mathrm{~m}$ to $985.5 \mathrm{~m}$. The distribution characteristics of the in-situ stress in the coalfield were studied. A finite-element numerical model was established for the optimization of the technical parameters of the support system of the roadway named "central air return rise" in the Kouzidong coal mine. The results showed that the stress characteristics directly affect the stability of the surrounding rock mass. Particularly, the roadway surrounding rock mass could be severely damaged when the coefficient of the non-uniform horizontal stress is higher than 1.8, the tectonic stress coefficient exceeds 1.4 , and the angle between the roadway strike and the maximum principal stress is larger than $75^{\circ}$. This study can provide a reference for in-situ stress measurement, stability analysis, and roadway support design for deep mines.
\end{abstract}

Keywords: In-situ stress measurement, Hollow-inclusion strain gauge method, Roadway support, Mining engineering

\section{Introduction}

More than $95 \%$ of the coal resources of China are extracted by underground mining methods, and more than $10,000 \mathrm{~km}$ of roadways and openings are excavated and supported each year [1]. In-situ stress is the initial stress in the crust before an engineering disturbance. It is the fundamental force that causes the surrounding rock deformation and destruction in a mine roadway. The deformation of underground rock structures and the stability of their surrounding rock masses are affected by the synthesis of the in-situ stress before excavation and the secondary stress (also called mininginduced stress). Secondary stress results from the stress redistribution in the coal-bearing strata. This stress redistribution is caused by the movement, deformation, and destruction of the surrounding rock mass after roadway excavation, and it depends on the in-situ stress [2]. Therefore, determining the in-situ stress state becomes an indispensable step before mine design, construction, and production. The magnitude and direction of the in-situ stress in a coal mine are critical factors in the mining process. Thus, in-situ stress

\footnotetext{
- E-mail address: qiliu@aust.edu.cn

ISSN: 1791-2377 @ 2016 Eastern Macedonia and Thrace Institute of Technology. All rights reserved.
}

measurement is a prerequisite for determining the mechanical properties of an engineering rock mass, conducting a stability analysis of the surrounding rock mass, and realizing the scientific design of underground excavation [3]. With the decrease in shallow coal resources and the shift to deep coal mining in China, the highly complex stress distributions in roadway surrounding rock masses and the abnormal pressure in coal mines have resulted in numerous instability problems, serious threats to coal mine safety, and a decline in production efficiency. Thus, the measurement and analysis of in-situ stress in deep mines have become increasingly important [4].

In this paper, a mathematical model for in-situ stress measurement based on a hollow-inclusion strain gauge (HISG) method was developed. A calculation formula for the principal stresses was also derived. The derivation is based on the elastic deformation hypothesis of a homogeneous isotropic rock, and the deformation analysis theory of a circular hole within the framework of elasticity mechanics. In-situ stress measurement was conducted in fifteen points in four deep mines in the Xinji coalfield in Anhui Province of China. The distribution characteristics of the in-situ stress and their influences on the deformation and failure of the roadway surrounding rock mass were investigated. Subsequently, a finite-element numerical 
model was established to optimize the technical parameters of the support system of the "central air return rise" roadway in the Kouzidong coal mine.

\section{State of the art}

Owing to the importance of in-situ stress measurement in mining engineering, hydraulic and hydropower engineering, civil construction, tunnel bridge construction, and other branches of rock engineering, numerous scholars in China and abroad have extensively studied in-situ stress measurement [5], [6], [7]. After decades of continuous effort and engineering developments, various techniques and methods have been proposed and widely applied to measure the in-situ stress in deep coal mines. These methods can be classified into six categories: hydraulic fracturing (HF) method, borehole stress relief (BHSR) method, flat-jack testing, strain recovery method, borehole caving method, and acoustic emission method. Among these categories, the HF method and BHSR method have become the most commonly used methods for in-situ stress measurement in underground coal mines [8], [9]. However, the latter has gradually become the first choice in the measurement of insitu stress in deep coal mines because a three-dimensional (3D) stress vector cannot be obtained by the HF method [10]. Furthermore, test equipment used in the HF method is bulky and expensive [11]. Therefore, the BHSR method was selected as the in-situ stress measurement method in our study.

HISG method is an example of a BHSR method by overcoring, which was introduced by Hast to measure the in-situ stress in the Scandinavian Peninsula[12], in the 1950 s. Since then, various types of stress gauges have been developed and improved for in-situ stress measurement, such as the deformation gauge of the United States Bureau of Mines; the doorstopper of the Council for Scientific and Industrial Research, South Africa (CSIR); the triaxial strain cell of the CSIR; the HISG of the Commonwealth Scientific and Industrial Research Organization, Australia; and the solid-inclusion cell of the University of New South Wales, Australia [13]. In 1995, Cai et al. [14] systematically tested and validated the performances of different types of stress gauges and found that HISGs presented the highest precision and were the most commonly used gauges for the measurement of in-situ stress under various rock conditions.

Subsequently, numerous scholars have conducted indepth studies on the factors detrimentally affecting the precision of the HISG method [15]. They have reached a consensus that the accuracy of in-situ stress measurement based on the HISG method mainly depends on three factors: (1) the influences of the epoxy and cement on the stress measurement accuracy, (2) the difference between the hypothetical and actual constitutive properties of a rock mass, and (3) the temperature variation during overcoring. To overcome these issues, Duncan Fama and Pender [16] conducted a complete mathematical analysis of the influences of the different elastic properties of epoxy resin and cement, as well as the position of the strain gauges in relation to the surface of the hole during in-situ stress measurement. In addition, Amadei [17] proposed new expressions for the residual stresses obtained with a solid- or hollow-inclusion stress probes in an anisotropic ground. Spathis [18] considered the time-dependent behaviors of circumferential strains in a viscoelastic epoxy-resin HISG bonded to an elastic host rock and presented a constitutive law for the host rock by analytical and numerical methods. A full temperature compensation technique was developed by Cai [19] on the basis of the Wheatstone bridge to ensure that the indicator did not record any unnecessary strain induced by a temperature change. On the basis of the constitutive equations for the rocks being studied, Cai and Peng [11] developed techniques to determine the effects of the nonlinearity, anisotropy, and discontinuity of rock masses on the accuracy of the in-situ stress calculation method, in which the rock stress is calculated using the measured strains. Han et al. [20] constructed a stress function to determine the stress near a borehole by stress calculus of variations and provided a theoretical basis for the evaluation of the in-situ stress in an anisotropic rock mass by using the theory of orthotropic elasticity.

These studies have shown the basic functional principles, structural features, and applications of various strain gauges in HISG-based in-situ stress measurement. However, further study is still necessary to improve the accuracy of in-situ stress measurement and extend its quantitative application in engineering. Therefore, in this study, theoretical derivation, field testing, and numerical simulation were performed to compensate for the limitations of the existing literature.

The remainder of this paper is organized as follows: Section 3 discusses the establishment of the mathematical model for HISG-based in-situ stress measurement and the derivation of the calculation formula for the principal stresses. Section 4 presents the details of the case study on the selected fifteen measurement points in four deep mines in the Xinji coalfield, the analysis of the in-situ stress distribution characteristics in the coalfield, and the optimization of the parameters of the support system of the central air return rise roadway in the Kouzidong coal mine. Section 5 presents the conclusions.

\section{Methodology}

For HISG-based in-situ stress measurement, three groups of resistance gauges were embedded with epoxy resin and spaced at equal intervals around the same circumference of a circle. Each group consisted of four strain gauges spaced at intervals of $45^{\circ}$ from the positive direction to the negative direction of the gauge axis. The strain gauges were installed on the wall of the test hole with epoxy resin. The gauge direction was parallel to the drilling axis, and the strain gauges were isolated from the surrounding rock mass with an annular core bit, until the glue between each strain gauge and the surrounding rock mass was firm. This setup allowed for the determination of the elastic stress release process of the tested rock mass during in-situ stress measurement [15]. In addition, strain changes were obtained using a highprecision strain device. Subsequently, the in-situ stress can be calculated on the basis of the relationship between the stress and strain of the tested rock mass. Therefore, the basic principle of the 3D HISG-based in-situ stress measurement can be analyzed by studying the stress and strain distributions around a circular hole in an isotropic elastic body.

\subsection{Mathematical model for HISG-based in-situ stress measurement}

According to the theory of elasticity, the stresses on the sides of a rectangular cube in a Cartesian coordinate system can be described with the assumption that the rock to be 
measured is an isotropic, continuous, and elastic body (Fig. 1(a)). When a borehole is drilled parallel to the $x$ axis in the cube, the stresses near the borehole are redistributed because of the influence of the borehole. Thus, the stress distribution in the rock around the borehole can be described using a cylindrical coordinate system ( Fig. 1(b)).

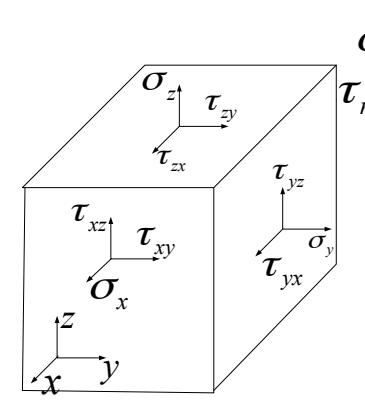

(a)

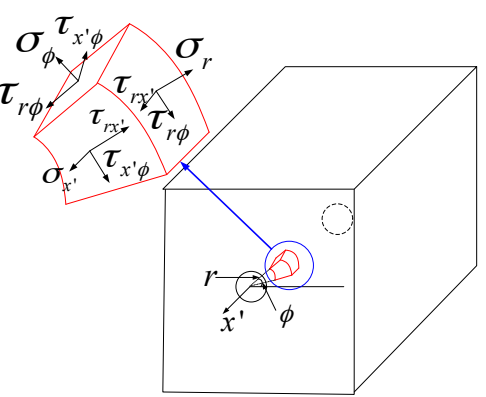

(b)
Fig.1. Stress distribution (a) before and (b) after borehole drilling.

As shown in Fig. 1, the six in-situ stress components in the rectangular coordinate system before borehole drilling can be denoted by $\sigma_{x}, \sigma_{y}, \sigma_{z}, \tau_{x y}, \tau_{y z}$, and $\tau_{z x}$, and the secondary stress components in the cylindrical coordinate system after borehole drilling can be denoted by $\sigma_{r}, \sigma_{\phi}, \sigma_{x^{\prime}}, \tau_{x^{\prime} \phi}, \tau_{r \phi^{\prime}}$ and $\tau_{r x^{\prime}}$

Therefore, on the basis of the theory of elasticity, the stress distribution around the borehole in an infinite body can be calculated by

$$
\left\{\begin{aligned}
\sigma_{r}= & \frac{\sigma_{y}+\sigma_{z}}{2}\left(1-\frac{R^{2}}{r^{2}}\right)+\frac{\sigma_{y}-\sigma_{z}}{2}\left(1-4 \frac{R^{2}}{r^{2}}+3 \frac{R^{4}}{r^{4}}\right) \cos 2 \phi \\
& +\tau_{y z}\left(1-4 \frac{R^{2}}{r^{2}}+3 \frac{R^{4}}{r^{4}}\right) \sin 2 \phi \\
\sigma_{\phi}= & \frac{\sigma_{y}+\sigma_{z}}{2}\left(1+\frac{R^{2}}{r^{2}}\right)-\left(1+3 \frac{R^{4}}{r^{4}}\right)\left(\frac{\sigma_{y}-\sigma_{z}}{2} \cos 2 \phi+\tau_{y z} \sin 2 \phi\right) \\
\sigma_{x^{\prime}}= & \sigma_{x}-2 \mu\left(\sigma_{y}-\sigma_{z}\right) \frac{R^{2}}{r^{2}} \cos 2 \phi-4 \mu \tau_{y z} \frac{R^{2}}{r^{2}} \sin 2 \phi \\
\tau_{x^{\prime} \phi}= & \left(1+\frac{R^{2}}{r^{2}}\right)\left(\tau_{z x} \cos \phi-\tau_{x y} \sin \phi\right) \\
\tau_{r \phi}= & \left(1+2 \frac{R^{2}}{r^{2}}-3 \frac{R^{4}}{r^{4}}\right)\left(\frac{\sigma_{y}-\sigma_{z}}{2} \sin 2 \phi+\tau_{y z} \cos 2 \phi\right) \\
\tau_{r x^{\prime}}= & \left(1-\frac{R^{2}}{r^{2}}\right)\left(\tau_{z x} \sin \phi+\tau_{x y} \cos \phi\right)
\end{aligned}\right.
$$

where $R$ is the radius of the borehole and $r$ is the calculated radius.

In consideration of the boundary conditions on the wall of the borehole (i.e., $R=r$ ), Eq. (1) can be rewritten as

$$
\left\{\begin{array}{l}
\sigma_{r}=\tau_{r x^{\prime}}=\tau_{r \phi}=0 \\
\sigma_{\phi}=\left(\sigma_{y}+\sigma_{z}\right)-2\left(\sigma_{y}-\sigma_{z}\right) \cos 2 \phi-4 \tau_{y z} \sin 2 \phi \\
\sigma_{x^{\prime}}=\sigma_{x}-2 \mu\left(\sigma_{y}-\sigma_{z}\right) \cos 2 \phi-4 \mu \tau_{y z} \sin 2 \phi \\
\tau_{\phi_{x^{\prime}}}=2 \tau_{z x} \cos \phi-2 \tau_{x y} \sin \phi
\end{array}\right.
$$

The relationship between the borehole stress and the corresponding strain can be determined by using the generalized Hooke's law.

$\left\{\begin{array}{l}\varepsilon_{\phi}=\frac{\sigma_{\phi}}{E}-\mu \frac{\sigma_{x^{\prime}}}{E} \\ \varepsilon_{x^{\prime}}=\frac{\sigma_{x^{\prime}}}{E}-\mu \frac{\sigma_{\phi}}{E} \\ \varepsilon_{45}=\frac{1+\mu}{E} \tau_{\phi x^{\prime}}+\frac{1-\mu}{2 E}\left(\sigma_{\phi}+\sigma_{x^{\prime}}\right)\end{array}\right.$

where $E$ is the elastic modulus of rock and $\mu$ is the Poisson's ratio of the rock mass.

Subsequently, the relationship can be described as follows:

$$
\left\{\begin{array}{l}
\varepsilon_{\phi}=\frac{\left(\sigma_{y}+\sigma_{z}\right)-2\left(\sigma_{y}-\sigma_{z}\right)\left(1-\mu^{2}\right) \cos 2 \phi-4 \tau_{y z}\left(1-\mu^{2}\right) \sin 2 \phi-\mu \sigma_{x}}{E} \\
\varepsilon_{r}=\frac{-\mu\left[\left(\sigma_{y}+\sigma_{z}\right)+2\left(\sigma_{y}-\sigma_{z}\right)(1+\mu) \cos 2 \phi-4 \tau_{y z}(1+\mu) \sin 2 \phi-\mu \sigma_{x}\right.}{E} \\
\varepsilon_{X^{\prime}}=\frac{\sigma_{x}-\mu\left(\sigma_{y}+\sigma_{z}\right)}{E} \\
\gamma_{\phi x^{\prime}}=\frac{4(1+\mu)\left(\tau_{x z} \cos \phi-\tau_{x y} \sin \phi\right)}{E}
\end{array}\right.
$$

After the released strains near the testing borehole wall were obtained by on-site overcoring stress measurement in the deep mine, the in-situ stress components $\sigma_{x}, \sigma_{y}, \sigma_{z}, \tau_{x y}, \tau_{y z},{ }^{\text {and }} \tau_{z x}$ could be calculated using Eqs. (1)-(4).

Currently, the reliability and accuracy of overcoring stress measurement have been significantly improved. The Institute of Geomechanics of the Chinese Academy of Geological Sciences has already applied the aforementioned principles and compensation techniques to develop a relatively mature HISG called KX-81 (Fig. 2). Full temperature compensation was achieved by these strain gauges by calibrating the thermal strain rate, recording the temperature changes during overcoring, and determining the additional thermal strain values in each strain gauge.

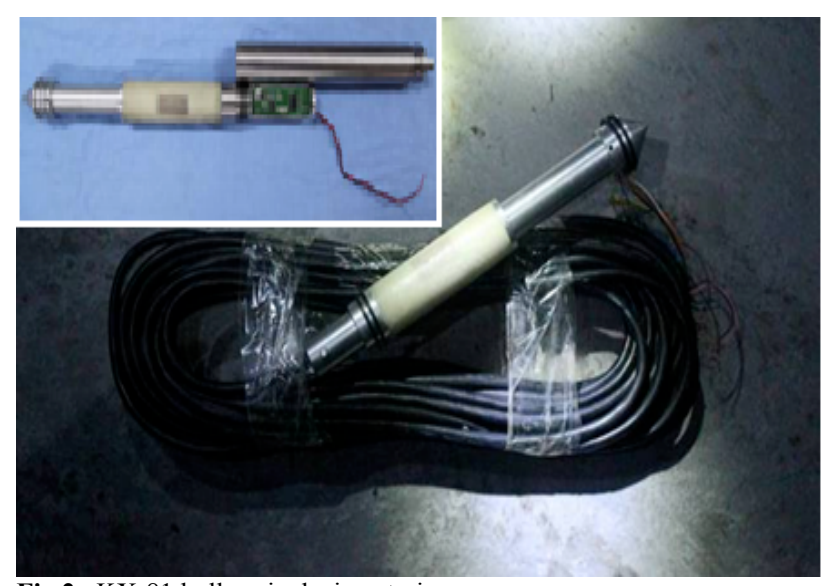

Fig.2. KX-81 hollow-inclusion strain gauge

\subsection{Calculation formula for the principal stresses}

The stress components $\sigma_{x}, \sigma_{y}, \sigma_{z}, \tau_{x y}, \tau_{y z}$, and $\tau_{z x}$ derived from Eqs. (1)-(4) are in a local coordinate system, whose $x$ 
axis is parallel to the drilling axis. Thus, these stress components are not exactly the in-situ stress, which refers to the original stress in the rock mass in the geographical reference system. And the in-situ stress should not be influenced by mining activities. Therefore, these stress components must be converted into the global stress components $\sigma_{X}, \sigma_{Y}, \sigma_{Z}, \tau_{X Y}, \tau_{Y Z}$, and $\tau_{Z X}$ in the geographical reference system. The global stress components can be obtained by

$$
\left(\sigma_{X}, \sigma_{Y}, \sigma_{Z}, \tau_{X Y}, \tau_{Y Z}, \tau_{z X}\right)^{T}=\Delta^{-1} \cdot\left(\sigma_{x}, \sigma_{y}, \sigma_{z}, \tau_{x y}, \tau_{y z}, \tau_{z x}\right)^{T}
$$

$$
\text { where }\left(\sigma_{X}, \sigma_{Y}, \sigma_{Z}, \tau_{X Y}, \tau_{Y Z}, \tau_{Z X}\right)^{T} \text { is the global stress }
$$

vector in the geographical reference system, $\left(\sigma_{x}, \sigma_{y}, \sigma_{z}, \tau_{x y}, \tau_{y z}, \tau_{z x}\right)^{T}$ is the local stress vector in the drilling reference system, and $\Delta$ is the stress transformation matrix $(6 \times 6)$, which can be expressed as

$$
\Delta=\left[\begin{array}{cccccc}
l_{1}^{2} & m_{1}^{2} & n_{1}^{2} & 2 l_{1} \cdot m_{1} & 2 m_{1} \cdot n_{1} & 2 n_{1} \cdot l_{1} \\
l_{2}^{2} & m_{2}^{2} & n_{2}^{2} & 2 l_{2} \cdot m_{2} & 2 m_{2} \cdot n_{2} & 2 n_{2} \cdot l_{2} \\
l_{2}^{2} & m_{2}^{2} & n_{3}^{2} & 2 l_{3} \cdot m_{3} & 2 m_{3} \cdot n_{3} & 2 n_{3} \cdot l_{3} \\
l_{1} \cdot l_{2} & m_{1} \cdot m_{2} & n_{1} \cdot n_{2} & l_{1} \cdot m_{2}+l_{2} \cdot m_{1} & m_{1} \cdot n_{2}+m_{2} \cdot n_{1} & n_{1} \cdot l_{2}+n_{2} \cdot l_{1} \\
l_{2} \cdot l_{3} & m_{2} \cdot m_{3} & n_{2} \cdot n_{3} & l_{2} \cdot m_{3}+l_{3} \cdot m_{2} & m_{2} \cdot n_{3}+m_{3} \cdot n_{2} & n_{2} \cdot l_{3}+n_{3} \cdot l_{2} \\
l_{3} \cdot l_{1} & m_{3} \cdot m_{1} & n_{3} \cdot n_{1} & l_{3} \cdot m_{1}+l_{1} \cdot m_{3} & m_{3} \cdot n_{1}+m_{1} \cdot n_{3} & n_{3} \cdot l_{1}+n_{1} \cdot l_{3}
\end{array}\right]
$$

where $l_{1}, l_{2}$, and $l_{3}$ are the direction cosines between the $x, y$, and $z$ axes in the local system and the $X$ axis in the geographical system; $m_{1}, m_{2}$, and $m_{3}$ are the direction cosines between the $x, y$, and $z$ axes in the local system and the $Y$ axis in the geographical system; $n_{1}, n_{2},{ }^{\text {and }} n_{3}$ are the direction cosines between the $x, y$, and $z$ axes in the local system and the $Z$ axis in the geographical system.

Therefore, the principal stresses can be obtained by

$$
\left|\begin{array}{ccc}
\sigma_{X}-\sigma & \tau_{X Y} & \tau_{X Z} \\
\tau_{X Y} & \sigma_{Y}-\sigma & \tau_{Y Z} \\
\tau_{X Z} & \tau_{Y Z} & \sigma_{Z}-\sigma
\end{array}\right|=0
$$

After the solutions to Eq. (7) are arranged from the largest to the smallest, all three principal stresses, namely, $\sigma_{1}, \sigma_{2}$, and $\sigma_{3}$, can be obtained. Subsequently, substitute them individually into the following equation to obtain the corresponding orientations and dips of the principal stresses in the global coordinate system:

$$
\left\{\begin{array}{l}
\left(\sigma_{X}-\sigma_{i}\right) l_{i}+\tau_{X Y} m_{i}+\tau_{X Z} n_{i}=0 \\
\tau_{X Y} l_{i}+\left(\sigma_{Y}-\sigma_{i}\right) m_{i}+\tau_{Y Z} n_{i}=0 \\
\tau_{X Z} l_{i}+\tau_{Y Z} m_{i}+\left(\sigma_{Z}-\sigma_{i}\right) n_{i}=0
\end{array}\right.
$$

where $\sigma_{i}(i=1,2,3)$ refers to the principal stresses $\sigma_{1}, \sigma_{2}$, and $\sigma_{3} ; l_{i}, m_{i}$, and $n_{i}$ are the direction cosines between the principal stress $\sigma_{i}(i=1,2,3)$ and the $X, Y$, and $Z$ axes in the geographical system.

\section{In-situ stress measurement and result analysis: A case study}

Four deep mines in the Xinji coalfield were considered for the case study to examine the feasibility of the established mathematical model for HISG-based in-situ stress measurement and the calculation formula for the principal stresses. Field in-situ stress measurement was performed, and the distribution characteristics of the in-situ stresses in the deep coal mines were analyzed.

\subsection{Geological background of the Xinji coalfield}

Xinji coalfield, which belongs to the State Development and Investment Corporation of China, has a total mining area of $1092 \mathrm{~km}^{2}$, coal reserves of 10.16 billion tons, and an annual approved production capacity of 15.55 million tons. In this coalfield, the geological conditions of the coal seams are complex and unstable, and they are affected by various faults, folds, collapse features, and other geological structures. In terms of geological structure, the Xinji coalfield extends from the west bank of the Huaihe River and Yingshang-Chenqiao fault in the east to the Kouziji fault in the west and stretches from the Xieqiao synclinal axis or the Yangcunji fault in the north to the Fufeng thrust fault or the Shouxian-Laorentou fault in the south (Fig. 3). In-situ stress is one of the most basic but critical factors influencing roadway stability. It has resulted in severe floor heave, breakage, and roadway damage every time the coalfield is mined. Therefore, clear and accurate information about the in-situ stress in the coalfield should be obtained, and the distribution law of the in-situ stress should be understood for the appropriate design of roadways, selection of support system, setting of work sequences, and other mining activities.

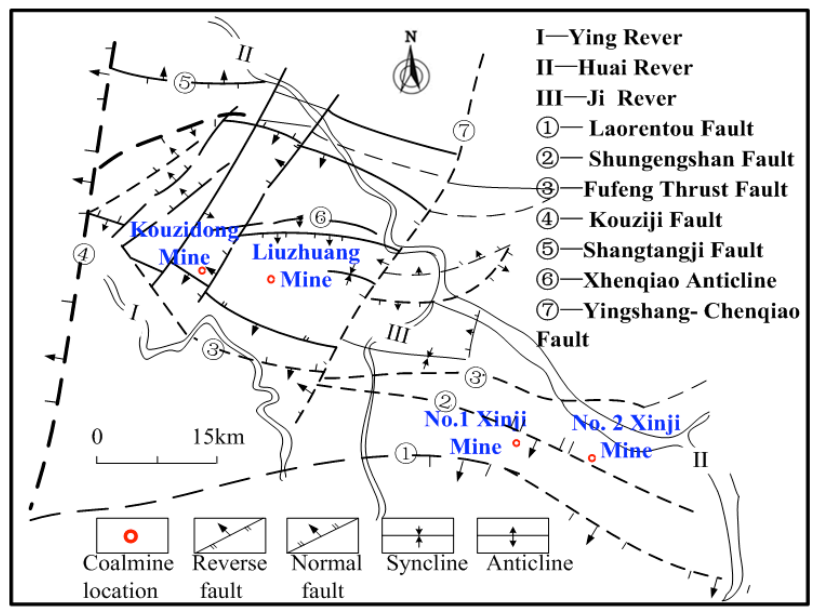

Fig.3. Schematic diagram of geological structure of the Xinji coalfield

\subsection{Execution of in-situ stress measurement}

To investigate the distribution characteristics of the in-situ stress in the Xinji coalfield, the researchers of the Key Laboratory of Safety and High-Efficiency Coal Mining of the Anhui University of Science and Technology collaborated with the technical staff of each coal mine and measured the in-situ stresses in the fifteen points, which 
were selected from the four deep mines in the Xinji coalfield. From these fifteen points, whose elevations ranged from $-580 \mathrm{~m}$ to $-967 \mathrm{~m}$, a huge amount of valuable data were obtained for use in the subsequent design and construction of the roadways in this coalfield.

The detailed method and steps of HISG-based in-situ stress measurement were already expounded in a previous study [4]; thus, they are not repeated in this paper because of space limitations. However, the measurement of in-situ stress is a highly precise and complex procedure, whose success rate remains to be very low. Satisfactory test results are difficult to achieve by only following the specified experimental procedure in existing studies [21]. Therefore, in this study, comprehensive technical solutions were developed to ensure the reliability of the test results. A summary of the details of the technical assurance measures are summarized as follows:

(1) Careful preparation of test regulations and normalization of operating procedures.

Before actual in-situ stress measurement, project meetings were arranged, a detailed implementation plan was designed, rigorous experimental procedures were set, emergency treatments in case of adverse situations were prepared, and penalties for the violations of the operating rules were identified.

(2) Team building and skills training.

Any error or deviation in the operation during the in-situ stress test may reduce the accuracy of the measurement data or even lead to a failure to acquire data. Therefore, a rigorous selection or recruitment of experienced personnel, including geological, drilling, and testing workers was conducted. Subsequently, all the experimenters underwent a rigorous skills training, and they should pass a test on in-situ stress measurement operational skills to ensure the reliability of the results.

(3) Testing equipment calibration and experimental operation visualization.

A 130-150 mm-diameter main borehole and a homocentric 36-38 mm-diameter pilot hole were drilled simultaneously using an especially adapted drilling bit (Fig. 4), which effectively guaranteed the concentricity and smoothness of the test hole. Before the strain gauges were installed, a rock borehole camera (model YTJ20) was used to investigate the lithology and structure of the surrounding rock mass and determine the optimum test positions. The rock borehole camera was also used to visualize the installation of the strain gauges (Fig. 5).

(4) Comprehensive analysis of the geological data and careful selection of measurement points.

Adequate investigation and analysis of the geological structures were necessary to select the representative geological units, in which the measurement points would be arranged. These geological units should not be affected by faults, folds, and other tectonic zones, and they should be favorable for in-situ stress measurement. The locations and parameters of the measured boreholes in the Xinji coalfield are presented in Fig. 6 and Table 1.

(5) Rigorous execution of the laboratory experiments and accurate acquisition of rock mechanical parameters.

In HISG-based in-situ stress measurement, the reliability of the stress test results depended not only on the field tests but also on the laboratory experiments and postprocessing of data collected. One of the most important experiments is the calibration test for the accurate acquisition of the elastic mechanical parameters immediately after overcoring. A calibration test for uniform surrounding pressure was adopted in the current study (Fig. 7).

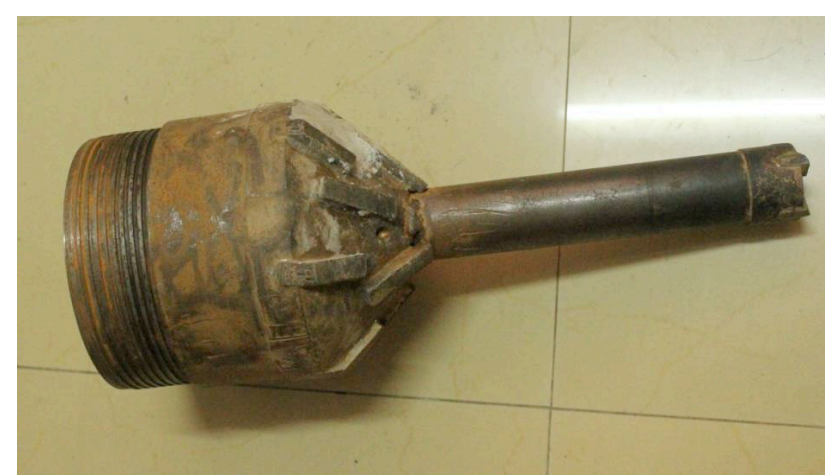

Fig.4. Especially adapted drilling bit

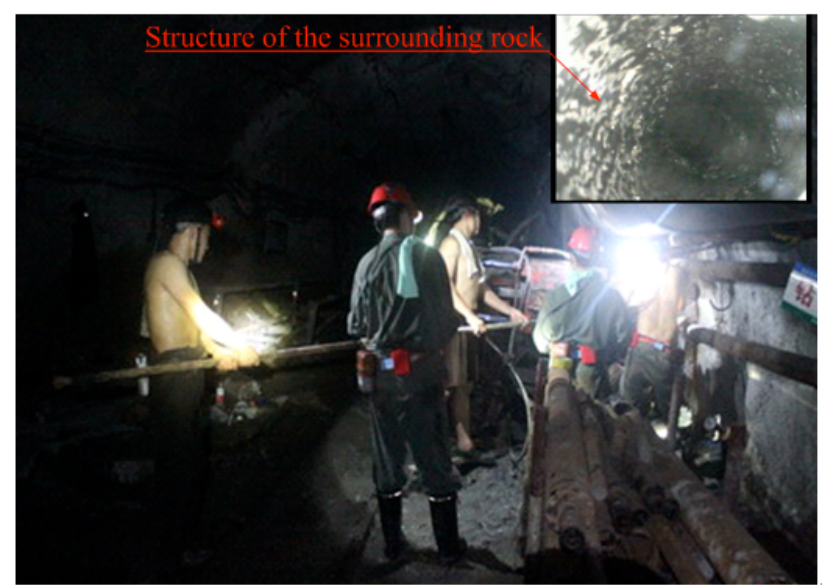

Fig. 5. Photographs of actual in-situ measurement

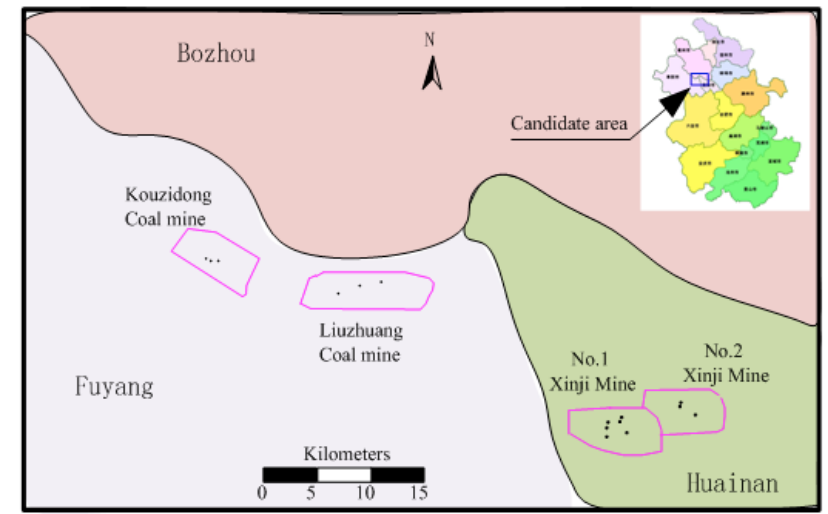

Fig. 6. Distribution of the measuring points in the Xinji coalfield

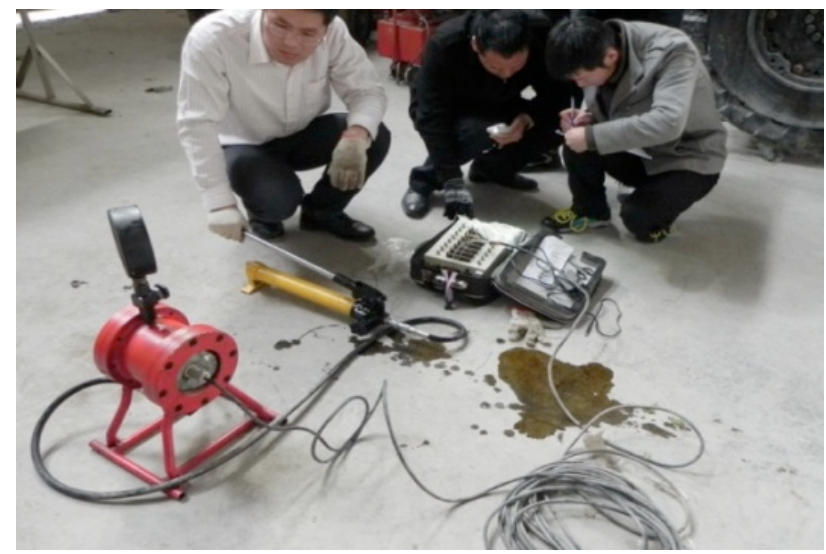

(a) 


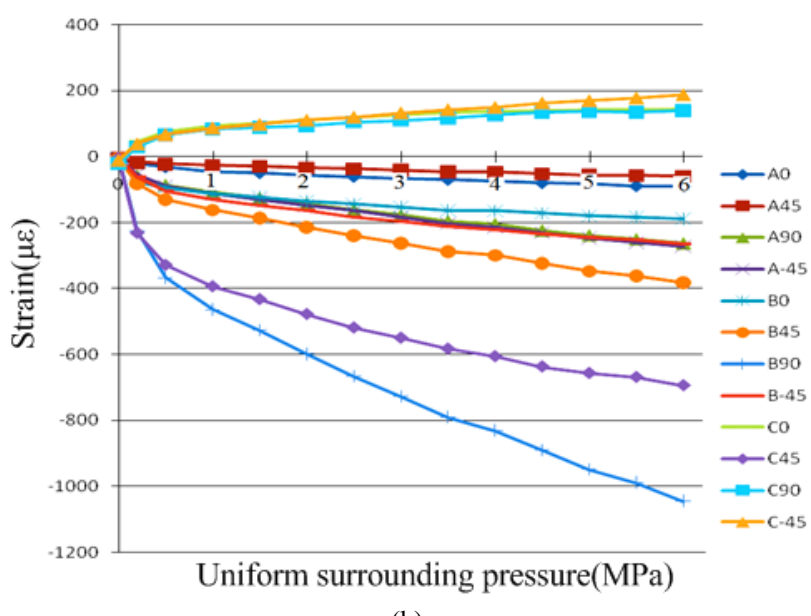

(b)
4.3 Analysis of the in-situ stress measurement results After the field tests, the stress-relief curves (Fig. 8) were generated to illustrate the variations in the strains on the 12 strain gauges with respect to the stress-relief distance.

As shown in Fig. 8, the stress-relief curves can be divided into three stages. Stage I is the no-evident-effect stage, in which the stress-relief distances range from 0 to 10 $15 \mathrm{~cm}$. Stage II is the elastic stress release stage, in which the corresponding stress-relief distances range from $15 \mathrm{~cm}$ to $25 \mathrm{~cm}$. Stage III is the approximately constant strain stage, in which the stress-relief distances exceed $25 \mathrm{~cm}$. Most of the obtained in-situ test results exhibit these typical characteristics, suggesting that the measurement and data acquisition procedures were scientific and reasonable. Thus, they can be used to calculate the in-situ stress.

Fig. 7. Calibration test for uniform surrounding pressure and its results. (a) Photograph. (b) Tested results

Table 1. Locations and parameters of the measured boreholes in the Xinji coalfield

\begin{tabular}{|c|c|c|c|c|c|c|}
\hline \multirow{2}{*}{ No. } & \multirow{2}{*}{ Coal mine } & \multirow{2}{*}{ Elevation(m) } & \multirow{2}{*}{ Buried depth(m) } & \multicolumn{3}{|c|}{ Measured boreholes } \\
\hline & & & & Length(m) & Orientation $\left({ }^{\circ}\right)$ & $\operatorname{Dip}\left({ }^{\circ}\right)$ \\
\hline AUST2012001 & \multirow{6}{*}{$\begin{array}{c}\text { No.1 } \\
\text { Xinji Mine }\end{array}$} & -580.0 & 605.0 & 12.00 & 110 & 0 \\
\hline AUST2012002 & & -580.0 & 605.0 & 11.55 & 180 & 0 \\
\hline AUST2012003 & & -700.0 & 725.0 & 10.65 & 90 & 5 \\
\hline AUST2012004 & & -580.0 & 605.0 & 11.20 & 295 & 3 \\
\hline AUST2012005 & & -700.0 & 725.0 & 11.50 & 205 & 3 \\
\hline AUST2012006 & & -700.0 & 725.0 & 12.50 & 85 & 3 \\
\hline AUST2012007 & \multirow{3}{*}{$\begin{array}{c}\text { No. } 2 \\
\text { Xinji Mine }\end{array}$} & -740.0 & 760.0 & 10.68 & 190 & 3 \\
\hline AUST2012008 & & -750.9 & 770.9 & 10.52 & 105 & 1.5 \\
\hline AUST2012009 & & -750.0 & 770.0 & 11.21 & 216 & 3 \\
\hline AUST2012010 & \multirow{3}{*}{$\begin{array}{l}\text { Liuzhuang } \\
\text { Coal mine }\end{array}$} & -743.6 & 770.6 & 12.57 & 180 & 3 \\
\hline AUST2012011 & & -750.7 & 777.7 & 9.72 & 358.5 & 1.5 \\
\hline AUST2012012 & & -749.6 & 776.6 & 10.28 & 178 & 5 \\
\hline AUST2012013 & \multirow{3}{*}{$\begin{array}{l}\text { Kouzidong } \\
\text { Coal mine }\end{array}$} & -960.5 & 987.5 & 8.00 & 100 & 2 \\
\hline AUST2012014 & & -958.5 & 985.5 & 9.47 & 164.5 & 4.5 \\
\hline AUST2012015 & & -958.3 & 985.3 & 7.77 & 134.5 & 3 \\
\hline
\end{tabular}

Table 2. Stress results in different measurement points in the Xinji coalfield

\begin{tabular}{|c|c|c|c|c|c|c|c|c|c|c|c|}
\hline \multirow[b]{2}{*}{ No. } & \multirow[b]{2}{*}{ Coal mine } & \multirow[b]{2}{*}{$\begin{array}{l}\text { Buried } \\
\operatorname{depth}(m)\end{array}$} & \multicolumn{3}{|c|}{ Maximum principal stress } & \multicolumn{3}{|c|}{ Intermediate principal stress } & \multicolumn{3}{|c|}{ Minimum principal stress } \\
\hline & & & $\begin{array}{l}\text { Value } \\
\text { (MPa) }\end{array}$ & $\begin{array}{l}\text { Orientatio } \\
n\left({ }^{\circ}\right)\end{array}$ & $\begin{array}{l}\text { Dip } \\
\left({ }^{\circ}\right)\end{array}$ & $\begin{array}{l}\text { Value } \\
\text { (MPa) }\end{array}$ & $\begin{array}{l}\text { Orientatio } \\
\mathbf{n}\left({ }^{\circ}\right)\end{array}$ & $\begin{array}{l}\text { Dip } \\
\left({ }^{\circ}\right)\end{array}$ & $\begin{array}{l}\text { Value } \\
\text { (MPa } \\
\text { ) }\end{array}$ & $\begin{array}{l}\text { Orientati } \\
\text { on }\left(^{\circ}\right)\end{array}$ & $\begin{array}{l}\text { Dip } \\
\left({ }^{\circ}\right)\end{array}$ \\
\hline $\begin{array}{l}\text { AUST2012001 } \\
\text { AUST2012002 } \\
\text { AUST2012003 } \\
\text { AUST2012004 } \\
\text { AUST2012005 } \\
\text { AUST2012006 }\end{array}$ & $\begin{array}{l}\text { No.1 } \\
\text { Xinji } \\
\text { Mine }\end{array}$ & $\begin{array}{l}605 \\
605 \\
725 \\
605 \\
725 \\
725 \\
\end{array}$ & $\begin{array}{l}17.8 \\
18.2 \\
20.5 \\
20.9 \\
23.5 \\
23.1 \\
\end{array}$ & $\begin{array}{l}87.83 \\
71.87 \\
92.5 \\
91.3 \\
89.2 \\
69.5 \\
\end{array}$ & $\begin{array}{l}2.97 \\
13.71 \\
19.48 \\
9.82 \\
13.76 \\
15.72 \\
\end{array}$ & $\begin{array}{l}13.2 \\
13.7 \\
14.7 \\
17.5 \\
18.0 \\
20.2 \\
\end{array}$ & $\begin{array}{l}-18.16 \\
160.57 \\
7.12 \\
187.1 \\
231.4 \\
112.5 \\
\end{array}$ & $\begin{array}{l}73.57 \\
66.72 \\
65.54 \\
67.02 \\
68.62 \\
-72.23 \\
\end{array}$ & $\begin{array}{l}10.2 \\
11.4 \\
11.2 \\
14.2 \\
13.6 \\
15.0 \\
\end{array}$ & $\begin{array}{l}174.45 \\
154.36 \\
121.86 \\
101.0 \\
179.1 \\
160.4 \\
\end{array}$ & $\begin{array}{l}-14.58 \\
18.34 \\
-14.43 \\
-8.97 \\
-6.75 \\
2.33 \\
\end{array}$ \\
\hline $\begin{array}{l}\text { AUST2012007 } \\
\text { AUST2012008 } \\
\text { AUST2012009 }\end{array}$ & $\begin{array}{l}\text { No.2 } \\
\text { Xinji } \\
\text { Mine }\end{array}$ & $\begin{array}{l}760 \\
770.9 \\
770 \\
\end{array}$ & $\begin{array}{l}24.0 \\
21.2 \\
22.6 \\
\end{array}$ & $\begin{array}{l}108.18 \\
103.83 \\
106.87 \\
\end{array}$ & $\begin{array}{l}-9.17 \\
11.31 \\
-2.08 \\
\end{array}$ & $\begin{array}{l}15.7 \\
15.2 \\
13.3 \\
\end{array}$ & $\begin{array}{l}75.46 \\
76.06 \\
45.37 \\
\end{array}$ & $\begin{array}{l}-59.98 \\
62.69 \\
-83.92 \\
\end{array}$ & $\begin{array}{l}9.4 \\
11.4 \\
10.1 \\
\end{array}$ & $\begin{array}{l}23.04 \\
193.85 \\
197.14 \\
\end{array}$ & $\begin{array}{l}-20.76 \\
16.04 \\
-15.38 \\
\end{array}$ \\
\hline $\begin{array}{l}\text { AUST2012010 } \\
\text { AUST2012011 } \\
\text { AUST2012012 }\end{array}$ & $\begin{array}{l}\text { Liuzhuang } \\
\text { Coal mine }\end{array}$ & $\begin{array}{l}770.6 \\
777.7 \\
776.6 \\
\end{array}$ & $\begin{array}{l}22.2 \\
20.8 \\
19.7 \\
\end{array}$ & $\begin{array}{l}96.18 \\
89.9 \\
87.95 \\
\end{array}$ & $\begin{array}{l}5.51 \\
15.11 \\
13.02 \\
\end{array}$ & $\begin{array}{l}16.5 \\
15.4 \\
16.4 \\
\end{array}$ & $\begin{array}{l}186.27 \\
259.11 \\
112.52 \\
\end{array}$ & $\begin{array}{l}-84.41 \\
74.63 \\
-75.74 \\
\end{array}$ & $\begin{array}{l}13.4 \\
11.3 \\
12.1 \\
\end{array}$ & $\begin{array}{l}197.78 \\
179.15 \\
179.28 \\
\end{array}$ & $\begin{array}{l}0.93 \\
-2.74 \\
5.73 \\
\end{array}$ \\
\hline $\begin{array}{l}\text { AUST2012013 } \\
\text { AUST2012014 } \\
\text { AUST2012015 }\end{array}$ & $\begin{array}{l}\text { Kouzidong } \\
\text { Coal mine }\end{array}$ & $\begin{array}{l}987.5 \\
985.5 \\
985.3 \\
\end{array}$ & $\begin{array}{l}30.2 \\
32.8 \\
36.1 \\
\end{array}$ & $\begin{array}{l}112.54 \\
120.71 \\
122.29\end{array}$ & $\begin{array}{l}9.01 \\
3.08 \\
1.48 \\
\end{array}$ & $\begin{array}{l}21.6 \\
20.6 \\
24.3 \\
\end{array}$ & $\begin{array}{l}178.79 \\
198.38 \\
202.09\end{array}$ & $\begin{array}{l}-69.54 \\
-57.31 \\
-69.47 \\
\end{array}$ & $\begin{array}{l}21.0 \\
14.0 \\
16.8 \\
\end{array}$ & $\begin{array}{l}25.43 \\
32.57 \\
33.28\end{array}$ & $\begin{array}{l}-22.32 \\
39.01 \\
18.54\end{array}$ \\
\hline
\end{tabular}

On the basis of the mathematical model for HISGbased in-situ stress measurement and the calculation formula for the principal stresses, the in-situ stress can be obtained by comprehensively analyzing the test data obtained during the field overcoring process and the laboratory calibration. The magnitudes, orientations, and dips of the in-situ stresses are listed in Table 2. The results show that the characteristics of the stress in each measurement point in the coalfield are consistent with the regional distribution laws of the in-situ stresses, clearly indicating the reliability of the proposed mathematical model and calculation formula. 


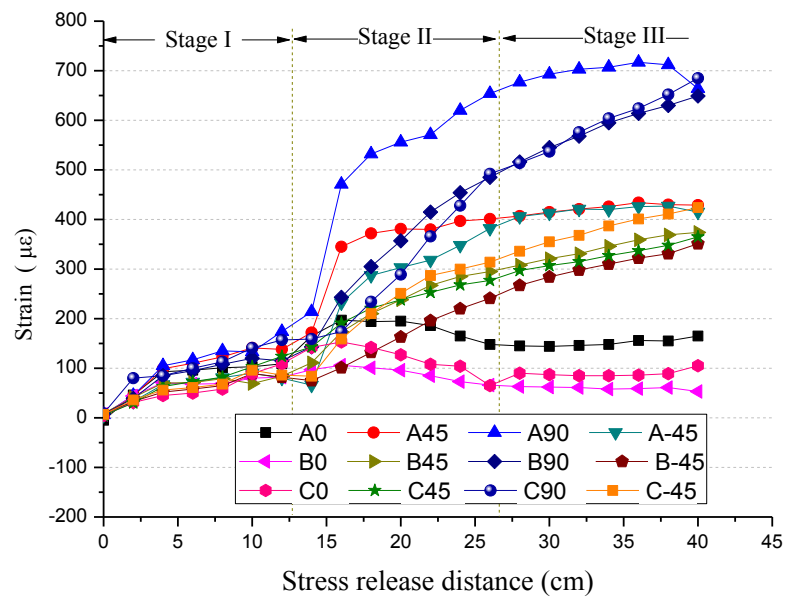

Fig. 8. Variations in strains with respect to the stress-relief distance

\subsection{Distribution characteristics of the in-situ stresses in} the Xinji coalfield

The distribution characteristics of the in-situ stresses in the Xinji coalfield were derived from the on-site measurement results in Table 2, which are illustrated in Fig. 9. The following conclusions can be drawn: (a) the maximum principal stress shows a dominant orientation, mainly varying between $\mathrm{N} 71^{\circ} \mathrm{E}$ and $\mathrm{N} 122^{\circ} \mathrm{E}$ with an average azimuth of $\mathrm{N} 96^{\circ} \mathrm{E}$. The minimum principal stress is approximately orthogonal to the maximum principal stress, although it is slightly divergent. However, the intermediate principal stress orientation is divergent, without obvious regularity. (b) The dip angles of the maximum principal stress and the minimum principal stress are both small, indicating that the horizontal tectonic stress dominates the entire stress field of the Xinji coalfield. (c) The intermediate principal stresses are nearly equal to the overburden pressures, and their dip angles are mostly greater than $60^{\circ}$.
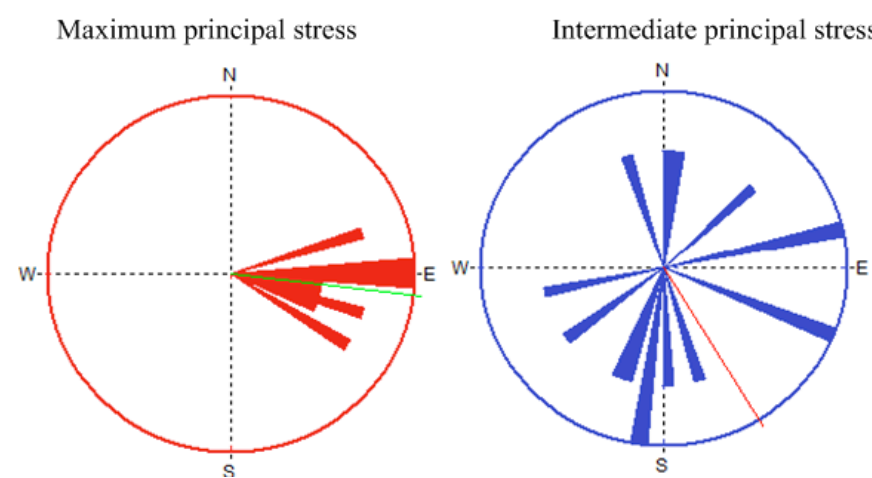

Intermediate principal stress

Minimum principal stress

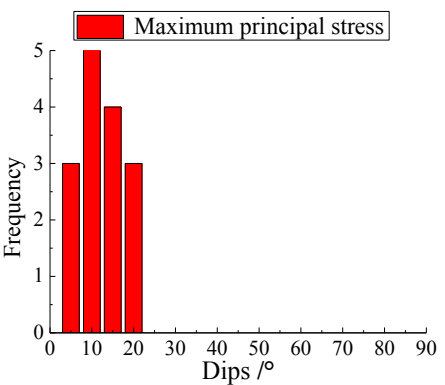

(a)

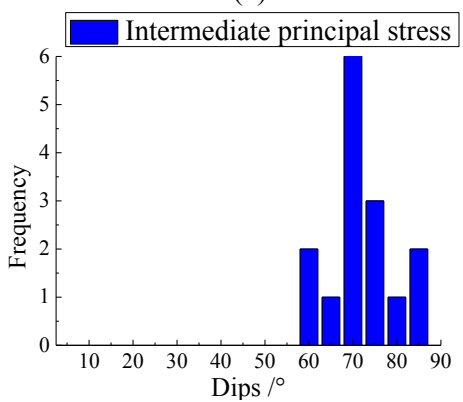

(b)
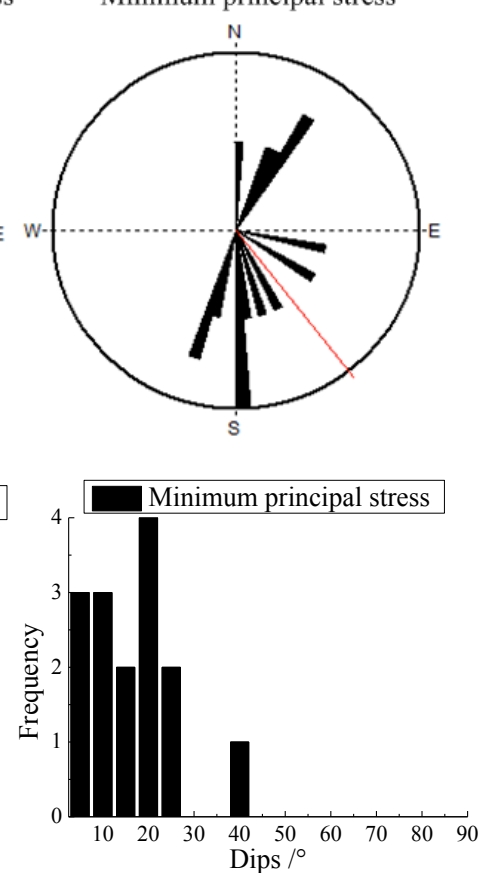

Fig. 9. Characteristics of the principal stresses in the Xinji coalfield. (a)Rose diagram of the orientations.(b) Statistical histogram of the dips

The spatial principal stress state restricts the application of in-situ stress measurement to mining production; thus, we obtained the horizontal maximum stress, horizontal minimum stress, and vertical stress (Table 3 ) by coordinate projection and calculation.

The results show that (a) the vertical stresses in the Xinji coalfield are approximately equal to the intermediate principal stress, as well as to the overburden pressure. (b) The relationship among the horizontal maximum stress $\left(\sigma_{H \max }\right)$, horizontal minimum stress $\left(\sigma_{H \min }\right)$, and vertical stress $\left(\sigma_{V}\right)$ is $\sigma_{H \max }>\sigma_{V}>\sigma_{H \text { min }}$. (c) The maximum tectonic stress coefficient (i.e., $\sigma_{H \max } / \sigma_{V}$ ) reaches 1.534 , and the gradient of the horizontal maximum stress reaches 3.783 , which is significantly greater than the average gravity of the overlying strata. This result indicates that the horizontal tectonic stress dominates the stress state of the studied coalfield. (d) The coefficients of the non-uniform horizontal stress (i.e., the ratio between the horizontal maximum stress and horizontal minimum stress) range from
1.386 to 1.903 and vary across different coal mines, indicating that the horizontal stress in the Xinji coalfield is obviously anisotropic. This variation has a significant effect on the layout of the mining working face and roadway excavation and support.

The relationship between the three stresses and depth were generated, as is shown in Fig. 10. And, the estimation formulas for the in-situ stresses in the Xinji coalfield can be obtained by mathematical fitting, as shown in the following:

(a) Horizontal maximum stress is

$\sigma_{H \max }=0.0323 D-0.3292, R=0.926$

(b) Vertical stress is

$\sigma_{v}=0.02321 D+1.834, R=0.9033$

(c) Horizontal minimum stress is 
$\sigma_{H \min }=0.01724 D+1.62369, R=0.8498$

where $D$ is the buried depth, and $R$ is the quadratic mean deviation.

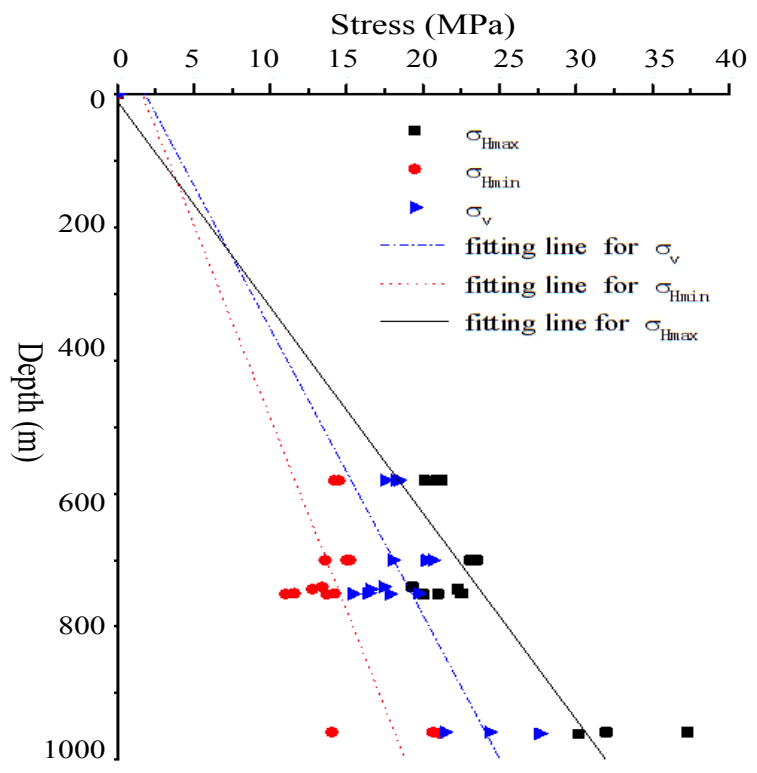

Fig. 10. Relationship between the stress values and depth

\subsection{Application of in-situ stress measurement to roadway support design}

As mentioned in Section 4.4, with an increase in buried depth, the difference among the horizontal maximum stress, horizontal minimum stress, and vertical stress increases, that is, the degree of stress anisotropy becomes remarkable as the depth increases. The relationship between the failure pattern of the roadway surrounding rock mass and the distribution characteristics of the in-situ stress was studied in the four deep mines in the Xinji coalfield by field observation and engineering sketching and drawing. The statistical results show that the anisotropy of the horizontal in-situ stress and the magnitude of the tectonic stress are important factors that influence the stability of the surrounding rock masses in roadways. If the coefficient of the non-uniform horizontal stress exceeds 1.8 and the tectonic stress coefficient exceeds 1.4, then the surrounding rock masses in the studied roadways show remarkable stability problems, such as considerable roof subsidence, obvious floor heave, and severe cases of separating and broken surrounding rock masses. Particularly, when the direction of the roadway axis is set inappropriately according to the dominant stress orientation, that is, the intersection angle is perpendicular or exceeds $75^{\circ}$, the surrounding rock mass is subject to serious damage [5], [22]. A typical failure diagram is shown in Fig. 11.

Table 3. Horizontal and vertical stresses in the Xinji coalfield

\begin{tabular}{|c|c|c|c|c|c|c|c|c|}
\hline No. & Coal mine & $\begin{array}{c}\text { Buried } \\
\operatorname{depth}(m)\end{array}$ & $\begin{array}{c}\text { Horizontal } \\
\text { maximum } \\
\text { stress } \\
(\mathrm{MPa})\end{array}$ & $\begin{array}{c}\text { Horizontal } \\
\text { minimum } \\
\text { stress } \\
(\mathrm{MPa})\end{array}$ & $\begin{array}{c}\text { Vertical } \\
\text { stress } \\
\text { (MPa) }\end{array}$ & $\begin{array}{l}\text { Non-uniform } \\
\text { coefficient of } \\
\text { horizontal } \\
\text { stress }\end{array}$ & $\begin{array}{c}\text { Maximum } \\
\text { tectonic } \\
\text { stress } \\
\text { coefficient }\end{array}$ & $\begin{array}{l}\text { Gradient of } \\
\text { Horizontal } \\
\text { maximum } \\
\text { stress } \\
\text { (MPa } / 100 \mathrm{~m})\end{array}$ \\
\hline AUST2012001 & \multirow{6}{*}{$\begin{array}{l}\text { No.1 } \\
\text { Xinji } \\
\text { Mine }\end{array}$} & 605.0 & 20.1 & 14.5 & 18.2 & 1.386 & 1.104 & 3.322 \\
\hline AUST2012002 & & 605.0 & 21.2 & 14.2 & 18.4 & 1.493 & 1.152 & 3.504 \\
\hline AUST2012003 & & 725.0 & 23.5 & 15.2 & 20.6 & 1.546 & 1.141 & 3.241 \\
\hline AUST2012004 & & 605.0 & 20.9 & 14.2 & 17.5 & 1.472 & 1.194 & 3.455 \\
\hline AUST2012005 & & 725.0 & 23.5 & 13.6 & 18.0 & 1.728 & 1.306 & 3.241 \\
\hline AUST2012006 & & 725.0 & 23.1 & 15.0 & 20.2 & 1.54 & 1.144 & 3.186 \\
\hline AUST2012007 & No.2 & 760.0 & 19.3 & 13.4 & 17.4 & 1.44 & 1.109 & 2.539 \\
\hline AUST2012008 & Xinji & 770.9 & 20.0 & 13.7 & 17.8 & 1.46 & 1.124 & 2.594 \\
\hline AUST2012009 & Mine & 770.0 & 22.5 & 14.2 & 19.7 & 1.585 & 1.142 & 2.922 \\
\hline AUST2012010 & \multirow{3}{*}{$\begin{array}{l}\text { Liuzhuang } \\
\text { Coal mine }\end{array}$} & 770.6 & 22.25 & 12.75 & 16.5 & 1.745 & 1.348 & 2.887 \\
\hline AUST2012011 & & 777.7 & 20.97 & 11.02 & 15.4 & 1.903 & 1.362 & 2.696 \\
\hline AUST2012012 & & 776.6 & 19.83 & 11.58 & 16.4 & 1.712 & 1.209 & 2.553 \\
\hline AUST2012013 & \multirow{3}{*}{$\begin{array}{l}\text { Kouzidong } \\
\text { Coal mine }\end{array}$} & 987.5 & 30.15 & 21.05 & 27.6 & 1.432 & 1.092 & 3.053 \\
\hline AUST2012014 & & 985.5 & 31.97 & 14.04 & 21.4 & 2.277 & 1.494 & 3.244 \\
\hline AUST2012015 & & 985.3 & 37.27 & 20.63 & 24.3 & 1.807 & 1.534 & 3.783 \\
\hline
\end{tabular}

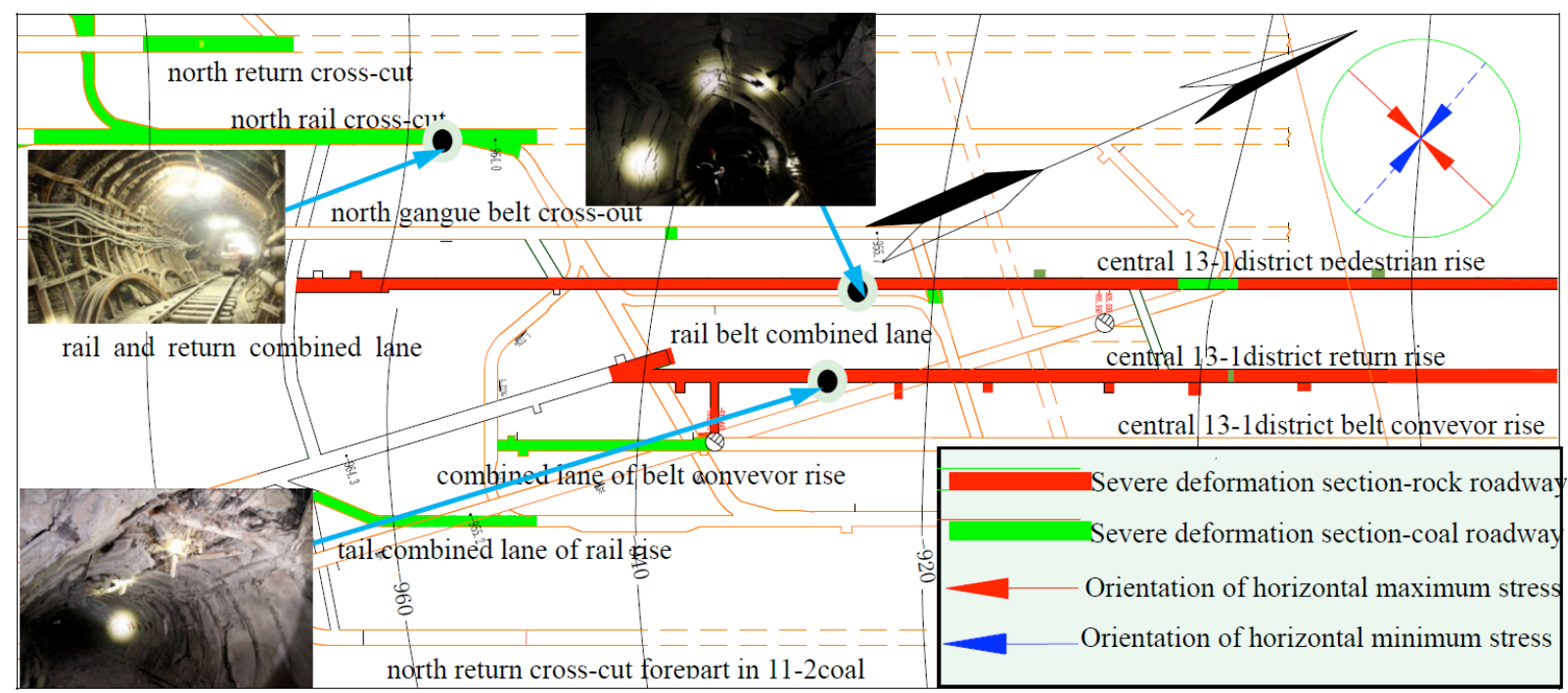

Fig. 11. Relationship between the failure of dilapidated roadway and in-situ stress distribution 
Therefore, engineers should understand the accurate distribution of the in-situ stress in a specific mining location. As an example, a finite-element numerical software package was used to establish the numerical simulation model for the optimization of the technical parameters of the support system for the studied roadway (i.e., central air return rise) in the Kouzidong coal mine, as shown in Fig. 12.

The roadway support system, which consists of anchor bolts, cables, and metal nets, was developed after several numerical simulations and optimization analyses. The main technical parameters of the system are listed in Table 4. Fig. 13 illustrates the differences in the roof and side displacements before and after the parameters of the support system were optimized using the in-situ stress measurement results. Both the roof convergence and roadway side displacement after parameter optimization are significantly less than those before optimization, in which only engineering experience is applied to the design. In summary, the actual support system becomes more economical and reasonable when in-situ stress information is used as basis.

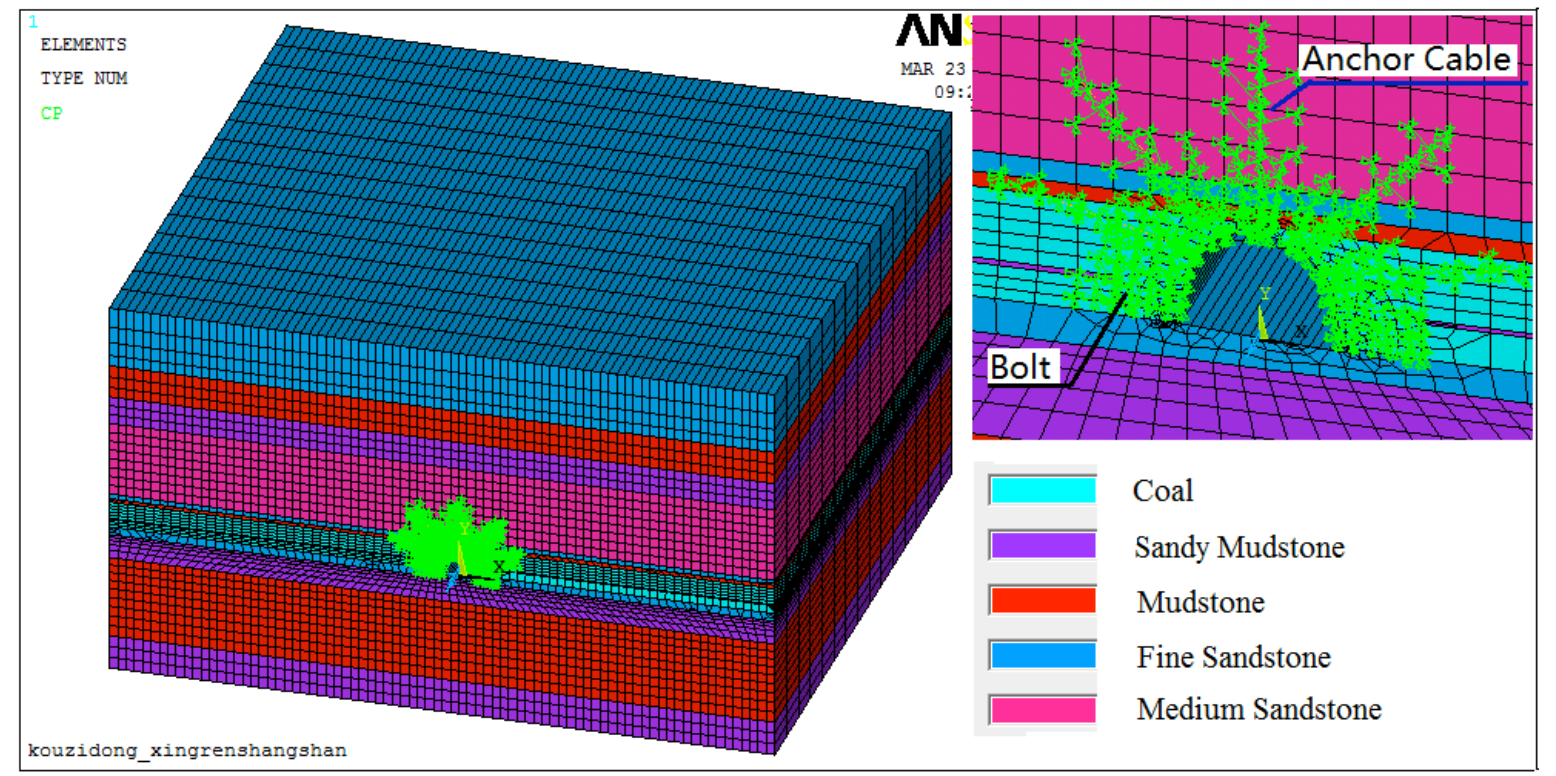

Fig. 12. Finite-element numerical model of the roadway bolt-cable support system

Table 4. Parameters of the support system for the studied roadway

\begin{tabular}{l|l|l}
\hline Item & Roadway roof & Roadway Side \\
\hline Bolt specifications & M24- $25 \times 2400 \mathrm{~mm}$ & M24- $\Phi 22 \times 2400 \mathrm{~mm}$ \\
Pre-tightening force & $\geq 80 \mathrm{KN}$ & $\geq 60 \mathrm{KN}$ \\
Anchorage force & $\geq 120 \mathrm{KN}$ & $\geq 120 \mathrm{KN}$ \\
Row \& Line Space of Bolt & $900 \mathrm{~mm} \times 800 \mathrm{~mm}$ & $900 \mathrm{~mm} \times 800 \mathrm{~mm}$ \\
Cable specifications & $\Phi 21.8 \mathrm{~mm} \times 9300 \mathrm{~mm}$ & $\Phi 21.8 \mathrm{~mm} \times 6300 \mathrm{~mm}$ \\
Row \& Line Space of Cable & $2400 \mathrm{~m} \times 800 \mathrm{~mm}$ & $2400 \mathrm{~m} \times 800 \mathrm{~mm}$ \\
\hline
\end{tabular}

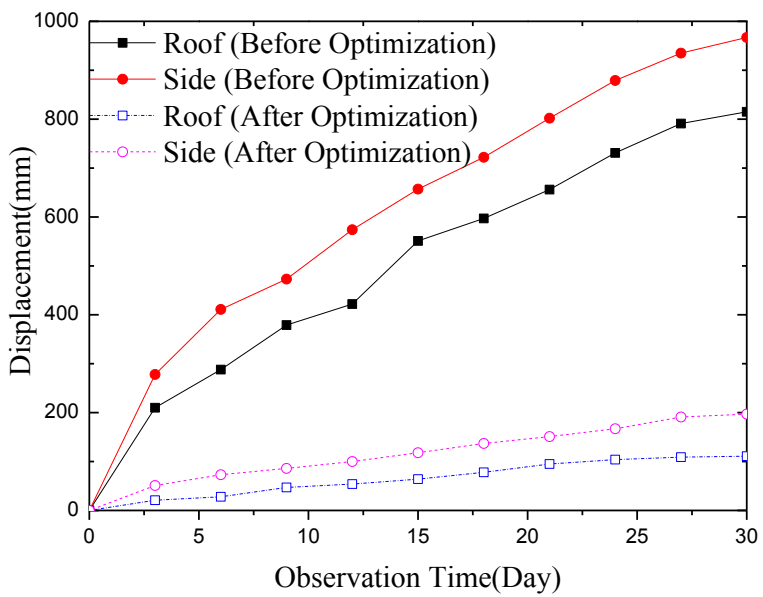

Fig. 13. Comparison of the rock displacements before and after the parameter optimization of the roadway support system

\section{Conclusions}

The distribution characteristics of in-situ stress play an important role in the stability of the roadway surrounding rock masses in deep coal mines. In this study, a mathematical model for HISG-based in-situ measurement and a calculation formula for principal stresses were established by theoretic cal analysis, experimental testing, numerical simulation, and field monitoring. Subsequently, the proposed model was applied to improve the stability control of the roadway surrounding rock masses in the Xinji coalfield. The contributions of this study are summarized as follows:

(1) The mathematical model for HISG-based in-situ stress measurement was established. The principal stress calculation formula was derived. Field measurement was performed in four deep mines in the Xinji coalfield. The distribution characteristics of the in-situ stress in the coalfield were determined. The results can provide useful information on the stability control of roadway surrounding rock masses in deep mine roadways.

(2) The relationship between the in-situ stress distribution and the failure pattern of the surrounding rock masses in the deep mines was examined. The results showed that the anisotropy of the horizontal in-situ stress and the high magnitude of the tectonic stress could lead to serious stability problems of the roadway surrounding rock masses. Particularly, when the coefficient of the non-uniform horizontal stress exceeds 1.8 , the tectonic stress coefficient exceeds 1.4 , and the angle between the roadway strike and 
the dominant stress orientation exceeds $75^{\circ}$, the surrounding rock mass is subject to serious damage.

(3) A numerical simulation model was established using a finite-element numerical software package to optimize the parameters of the roadway support system, which consists of anchor bolts, cables, and metal nets. Field inspection and monitoring were conducted during mining production, and the results of which indicated that the roadway support design based on actual in-situ stress information improved not only surrounding rock stability control but also cost efficiency.

This study can provide a scientific basis for in-situ stress measurement and roadway support system design in deep mines. However, the analysis and application of in-situ stress measurement in the coal mining production process is highly complex. Therefore, we intend to conduct further research on the reliability analysis, error estimation, and an efficient and reliable support technology based on the in-situ stress in roadways to maximize the use of the valuable stress information obtained, and other topics on in-situ stress.

\section{Acknowledgements}

The study was partially supported by the National Natural Science Foundation of China $(51374011,51634007)$ and the Young Teachers Program of Anhui University of Science \& Technology (QN201430).

\section{References}

1. Kang, H. P., Zhang, X., Si, L. P., Wu, Y., Gao, F., "In-situ stress measurements and stress distribution characteristics in underground coal mines in China". Engineering Geology, 116(3),2010, pp.333-345.

2. Hudson, J. A., Harrison, J. P., "Engineering rock mechanics-an introduction to the principles". Oxford: Pergamon Press, England, 2000, pp. 41-58.

3. Yang, X., Pang, J., Lou, H., \& Fan, L., "Characteristics of in situ stress field at Qingshui coal mine”. International Journal of Mining Science and Technology, 25(3), 2015, pp.497-501.

4. He, M. C., Qian, Q. H., "Summary of basic research on rock mechanics at great depth". In: Proceedings of the 9th symposium on rock mechanics and engineering, Beijing, China: Science Press, 2006, pp.49-62.

5. Ferrero, A. M., Migliazza, M., Segalini, A., Gullì, D., “ In situ stress measurements interpretations in large underground marble quarry by $3 \mathrm{D}$ modeling". International Journal of Rock Mechanics and Mining Sciences, 60(8), 2013, pp.103-113.

6. Ljunggren, C., Chang, Y., Janson, T., Christiansson, R, "An overview of rock stress measurement methods". International Journal of Rock Mechanics and Mining Sciences, 40(7), 2003, pp.975-989.

7. Chistiansson, R., "The latest development for in-situ rock stress measuring techniques". In: Proceedings of the International Symposium on In-situ Rock Stress, Trondheim, Norway: CRC Press, 2006, pp.3-10.

8. Amadei, B., Stephansson, O., "Rock stress and its measurement". Berlin: Springer Netherlands, Germany, 1997, pp.95-120.

9. Worotnicki, G., "Comprehensive rock engineering: principles, practices \& projects. Volume 3. Rock testing and site characterization". Oxford: Pergamon Press, England, 1993, pp.329-394.

10. Ge, X. R., Hou, M. X., "Principle of in-situ 3D rock stress measurement with borehole wall stress relief method and its preliminary applications to determination of in-situ rock stress orientation and magnitude in Jinping hydropower station". Science China Technological Sciences, 55(4), 2012, pp.939-949.

11. Cai, M. F., Peng, H., "Advance of in-situ stress measurement in China”. Journal of Rock Mechanics and Geotechnical Engineering, 3(4), 2011, pp.373-384.
12. Kurlenya, M., "Determining rock stress by strain relief in a core with a central borehole". Journal of Mining Science, 2(1), 1966, pp.8084.

13. Guo, Q., Ren, F., Guo, H., Zhao, L., Yan, Z., "Research on Hollow Inclusion Strain Sensors with Temperature Compensation Employed for In-situ Stress Monitor Network". Indonesian Journal of Electrical Engineering and Computer Science, 11(11), 2013, pp. 6296-6303.

14. Cai, M., Qiao, L., Yu, J., "Study and tests of techniques for increasing overcoring stress measurement accuracy". International Journal of Rock Mechanics and Mining Sciences and Geomechanics, 32(4), 1995, pp. 375-384.

15. Fairhurst, C., "Stress estimation in rock: a brief history and review". International Journal of Rock Mechanics and Mining Sciences, 40(7), 2003, pp.957-973.

16. Duncan Fama, M. E., Pender, M. J., "Analysis of the hollow inclusion technique for measuring in situ rock stress". International Journal of Rock Mechanics and Mining Sciences, 17(3), 1980, pp.137146.

17. Amadei, B., "Applicability of the theory of hollow inclusions for overcoring stress measurements in rock". Rock mechanics and rock engineering, 18(2), 1985, pp.107-130.

18. Spathis, A. T., "A biaxial viscoelastic analysis of hollow inclusion gauges with implications for stress monitoring”. International Journal of Rock Mechanics and Mining Sciences, 25(6), 1988, pp. 473-477.

19. Cai, M. F., "Studies of temperature compensation techniques in rock stress measurements". Chinese Journal of Rock Mechanics and Engineering, 10(3), 1991, pp.227-235. (in Chinese)

20. Han, C. R., Bai, S. W., Zhang, B., "Analysis of stress distribution near borehole in orthotropic rockmass with stress calculus of variations". Rock and Soil Mechanics, 28(12), 2007, pp.2593-2597. (In Chinese)

21. Reinecker, J., Stephansson, O., Zang, A., "Guidelines for the analysis of overcoring data". Scientific Technical Report 16-01, 2016, pp. 43-48.

22. Coggan, J., Gao, F., Stead, D., Elmo, D., "Numerical modelling of the effects of weak immediate roof lithology on coal mine roadway stability". International Journal of Coal Geology, 90-91, 2012, pp.100109. 